\title{
Knowledge and skills amongst optometrists in public and private sectors in India
}

\begin{tabular}{|c|c|}
\hline $\begin{array}{l}\text { Authors: } \\
\text { Anitha Arvind } \\
\text { Peter C. Clarke } \\
\text { Kovin S. Naido }\end{array}$ & $\begin{array}{l}{ }^{1} \\
-F^{3}\end{array}$ \\
\hline $\begin{array}{l}\text { Affiliations: } \\
{ }^{1} \text { African Vision } \\
\text { Institute, Colle } \\
\text { Sciences, Univ } \\
\text { KwaZulu-Natal } \\
\text { South Africa }\end{array}$ & $\begin{array}{l}\text { Research } \\
\text { ge of Health } \\
\text { ersity of } \\
\text {, Durban, }\end{array}$ \\
\hline $\begin{array}{l}{ }^{2} \text { Department } \\
\text { Sciences, Facu } \\
\text { and Wellness } \\
\text { Peninsula Univ } \\
\text { Technology, Ca } \\
\text { South Africa }\end{array}$ & $\begin{array}{l}\text { Ophthalmic } \\
\text { Ity of Health } \\
\text { Sciences, Cape } \\
\text { Jersity of } \\
\text { ape Town, }\end{array}$ \\
\hline $\begin{array}{l}{ }^{3} \text { Discipline of } \\
\text { College of Hea } \\
\text { University of } \\
\text { Durban, South }\end{array}$ & $\begin{array}{l}\text { ptometry, } \\
\text { lth Sciences, } \\
\text { waZulu-Natal, } \\
\text { Africa }\end{array}$ \\
\hline $\begin{array}{l}\text { Corresponding } \\
\text { Anitha Arvind, } \\
\text { anitha2001arv } \\
\text { com }\end{array}$ & $\begin{array}{l}\text { g author: } \\
\text { ind@gmail. }\end{array}$ \\
\hline $\begin{array}{l}\text { Dates: } \\
\text { Received: } 11 \mathrm{D} \\
\text { Accepted: } 17 \\
\text { Published: } 08\end{array}$ & $\begin{array}{l}\text { ec. } 2020 \\
\text { Dct. } 2021 \\
\text { Dec. } 2021\end{array}$ \\
\hline $\begin{array}{l}\text { How to cite th } \\
\text { Arvind A, Clark } \\
\text { Naidoo KS. Kn } \\
\text { skills amongst } \\
\text { in public and p } \\
\text { in India. Afr Vi } \\
\text { Health. 2021;8 } \\
\text { https://doi.org } \\
\text { aveh.v80i1.643 }\end{array}$ & $\begin{array}{l}\text { is article: } \\
\text { ke-Farr PC, } \\
\text { owledge and } \\
\text { optometrists } \\
\text { orivate sectors } \\
\text { sion Eye } \\
30(1) \text {, a643. } \\
\text { /10.4102/ } \\
3\end{array}$ \\
\hline $\begin{array}{l}\text { Copyright: } \\
\text { C 2021. The A } \\
\text { Licensee: AOS } \\
\text { is licensed und } \\
\text { Creative Comn } \\
\text { Attribution Lic }\end{array}$ & $\begin{array}{l}\text { uthor(s). } \\
\text { IS. This work } \\
\text { ler the } \\
\text { nons } \\
\text { ense. }\end{array}$ \\
\hline Read online: & \\
\hline 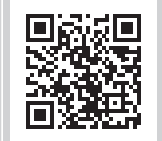 & $\begin{array}{l}\text { Scan this QR } \\
\text { code with your } \\
\text { smart phone or } \\
\text { mobile device } \\
\text { to read online. }\end{array}$ \\
\hline
\end{tabular}

Background: Optometrists with different levels of optometric education in India provide eye care services under various capacities to the public.

Aim: The study evaluated the status of optometrists in terms of their knowledge, skills and frequency of skill utilisation in public and private sectors.

Setting: A quantitative study design was adopted using a survey questionnaire that was distributed to optometrists providing eye care services in public and private sectors.

Methods: A structured and validated questionnaire with closed-ended questions was administered to 650 participants.

Results: A total of 400 completed questionnaires were received (response rate $=62 \%$ ) of which 207 respondents were males (52\%) and 193 females (48\%). Most (57\%) of the respondents were bachelor's degree holders with $86 \%$ of the respondents in the private sector and $14 \%$ in the public sector. The knowledge level of ancillary and diagnostic tests (69\%) was the least amongst public sector optometrists whilst it was binocular indirect ophthalmoscopy (66\%) for private sector optometrists. The skill levels in indirect ophthalmoscopy was least amongst the public sector $(56 \%)$ and private sector $(44 \%)$ optometrists. Indirect ophthalmoscopy showed the least frequency of skill utilisation amongst public sector (13\%) and private sector (34\%) optometrists.

Conclusion: The study highlighted the need for mandating best practice standards, and expanding the scope of defined practice, as optometrists are better suited for diagnostic roles and comprehensive eye examinations, and can contribute effectively towards averting preventable blindness.

Keywords: optometry skills; knowledge; skill level; skill utilisation; public sector; private sector.

\section{Introduction}

In India, optometry has made tremendous progress in terms of education and service delivery since the establishment of the first school of optometry in 1958. In many parts of the world, optometry is recognised as an independent profession offering primary eye care services and it is enacted into health legislation..$^{1,2}$ However, India is yet to recognise optometry as an independent primary eye care profession. The scope of practice of optometry varies from country to country and in India, it is poorly defined. . $^{3,4}$

India with a population of 1.3 billion has 9000 optometrists who have undergone four years of degree level education in optometry and 40000 ophthalmic technicians/assistants who have undergone two years of diploma education in ophthalmic training. ${ }^{5}$ Almost all developed countries (including the United States, United Kingdom, Australia and Canada) with optometry as a recognised profession have restrictions on who may provide eye examinations and who may prescribe and dispense optical appliances. ${ }^{6}$ In India there are no such restrictions as there is no regulatory body governing either the dispensing of optical appliances or optometric eye care. In India, optometry education is offered at diploma (2 years) or degree (4 years) levels. Several universities also offer post-graduation (2 years) and $\mathrm{PhD}$ in optometry specialities as well in the recent past. The diploma programme first established in the year 1958 comprises a 2-year course and the curriculum is more oriented towards ophthalmology, preparing students for practice under the supervision of ophthalmologists whereas the undergraduate programme which was first started in the year 1985 is structured in such a way that it prepares students for independent practice within the scope of optometry. Lack of standardisation of programmes, disparate entry and exit competencies, poorly defined career paths and unequal scope of practice for optometrists and Mid-Level Ophthalmic Personnel (MLOP) are major causes for concern in India and other countries where the profession is unregulated. ${ }^{7,99}$ Because 
of an unregulated optometry environment, there is neither a central registry for all optometrists in the country nor is there any information on service delivery and its contribution to the Indian eye care system. ${ }^{4}$ Furthermore, the level of education and the scope of practice is varied. ${ }^{4}$ In the Indian healthcare system, statutory bodies exist for doctors, nurses, pharmacists and dental practitioners, but there is no regulatory structure for optometrists. The state's medical council recognises ophthalmic assistants (diploma holders) under the paramedical council and registers them under the same..$^{10,11}$ Earlier government jobs were offered to diploma holders (ophthalmic assistants) only, but in the recent years government jobs for diploma and degree holders were recognised by the Ministry of Health and Family Welfare (MOHFW) and posts opened for optometrists in government setups. ${ }^{10,12}$ Optometrists in India provide primary eye care services under different capacities to the public (Table 1). Most optometrists offer their services in hospitalbased practice followed by academia and optical retail. ${ }^{4}$ In the private sector optometrists are presently placed in hospitals, optical outlets or stand-alone practices whilst in the public sector they are placed as state or central government employees providing eye care at the primary and secondary level. ${ }^{6}$ The primary eye care services in India are integrated into the healthcare system offering refraction and screening of common ocular conditions at the community or primary health centres catering for a population ranging between 30000 and $100000 .^{13}$ The Para Medical Ophthalmic Assistant (PMOA) who are diploma holders offer services at the primary level and make referrals. At secondary eye care centres ophthalmological services are offered including surgeries. An Internet-based questionnaire study on 4-year trained optometrists documented the example of optometry practice and scope of administration in India, but the study had limitations as it omitted most optometrists with education ranging between two and four years. ${ }^{4}$ This study evaluated the status of optometrists in terms of their knowledge and skill levels, and frequency of optometric skill utilisation in private and public sectors.

\section{Subjects and methods}

The participants in the study were involved in providing optometry services in public or private practice having at least two years or more formal education in optometry in accordance with the Indian Optometry Federation (IOF) nomenclature of 'Optometrist' in India. ${ }^{6}$

\section{Methodology}

A comprehensive review of the literature was undertaken and based on this a questionnaire was developed to evaluate optometrists in terms of their knowledge, skill levels and frequency of skill utilisation in private and public sectors, and to establish what the optometrist is capable of against what he or she is presently practising.

\section{Study design and duration}

A quantitative study design was adopted using a validated questionnaire to collect responses from optometrists rendering optometry services in the public and private sectors. This study was conducted between June and September 2018. A stratified random sampling method was employed with a sample size of 400 participants. The stratified population consisted of 90004 -year trained optometrists and 40000 2-year trained optometrists. ${ }^{5}$ Participation in this study was voluntary. Currently, there is no central registry for diploma and degree holders in optometry in India.

\section{Development of the questionnaire}

The study was conducted using a validated survey questionnaire with closed-ended questions. The questionnaire included demographic data consisting of age, gender, current job title and years of experience in the present designation followed by the area of practice. The questionnaire consisted of 14 skill sets, which were identified by the World Council of Optometry (WCO) as necessary to conduct a comprehensive eye examination by an optometrist. The respondent had to score each skill listed based on knowledge level, skill level as well as frequency of skill utilisation on a five-point Likert scale where ' 1 ' indicated poor knowledge/skill level and ' 5 ' indicated excellent knowledge/skill level. Similarly, the frequency of the performing skill was graded between 1 and 5 where 1 indicated never and 5 indicated always performing the skill. The information sheet and consent forms were distributed to all the respondents. Then, they were received back from them and stored as hard copy.

\section{Reliability and validity of the questionnaire}

The reliability of the questionnaire was tested using Cronbach's alpha and test-retest reliability. The first 50 respondents to the questionnaire were administered the questionnaire again within a gap of 15 days to check for test-retest reliability. The Cronbach's alpha was computed for all items in the questionnaire. A score of 0.80 and above implied a high correlation between items, thus indicating the questionnaire to be consistently reliable. Wilcoxon's non-parametric statistical test showed that there was no statistical difference in the results obtained between the two tests indicating a high degree of reliability.

\section{Validation of the questionnaire}

The questionnaire was validated by two methods - face validation as well as content validation. The questionnaire used in the study was face validated by six experts outside of the research area in the field of optometry. The experts involved in face validation included optometrists practising in public sector, private sector as well as academicians. Seven experts in the field of optometry in India were involved in content validation of the questionnaire. The seven experts included optometrists offering eye care services to the public in various set-ups in public and private sectors such as hospitals (eye hospitals), clinics and optical outlets. The experts were asked to rate the relevance of each item on the questionnaire on a fourpoint Likert scale of ' 1 ' not relevant ' 2 ' somewhat relevant ' 3 ' quite relevant and ' 4 ' highly relevant. The Content Validation Index (CVI) was computed for each item taking those answers relevant with a score of three and four on the Likert scale and 
TABLE 1: Overall analysis of knowledge, skill level and frequency of optometry skill utilisation between public and private sector optometrists in the study.

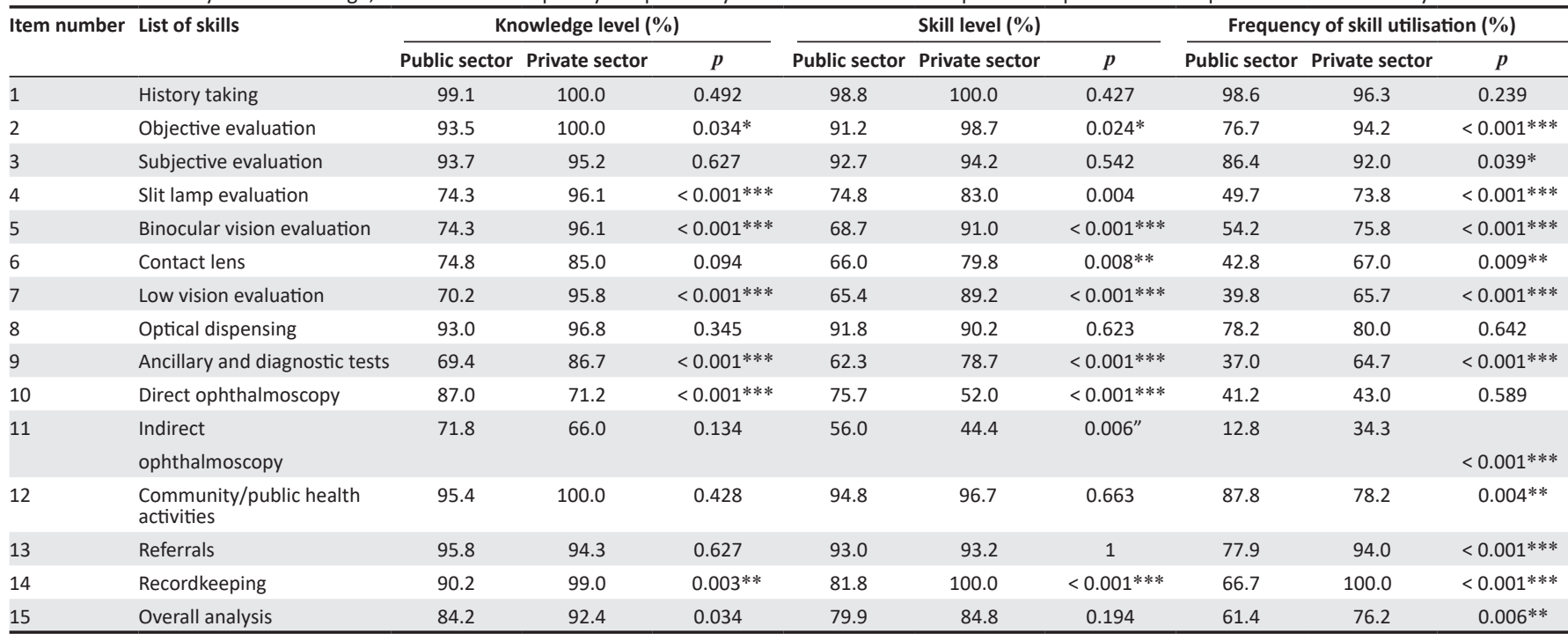

*, Significant; **, highly significant; ***, very high significant.

omitting those with a score of one and two on the Likert scale as non-relevant. The Individual Content Validity Index (I-CVI), Scale Level Content Validity Index with the average method (S-CVI/Average) and Scale level Content Validity with universal average (S-CVI/UA) were measured. The I-CVI score for each item was 0.86 and above, thus indicating that it had good individual content validity. The score for scale CVI with the average method was 0.86 implying excellent validity whilst the score for scale CVI with universal average was 0.91, wherein any score above 0.90 was considered excellent validity.

\section{Administering and recording questionnaire data}

\section{Data capture and analysis}

The data captured was analysed based on the variables for qualification, gender and sector of practice. Frequencies and percentages as well as non-parametric statistics such as Chisquare tests and Kendell's tau-b were used for analysis.

\section{Ethical considerations}

Ethical clearance was obtained from the Humanities and Social Sciences Research Ethics committee (HSSREC) from a large public university prior to administering the questionnaire (protocol reference number: HSS/1635/017D). The questionnaire was distributed both as hard and soft copies to practising optometrists across the country via electronic mail and post. All responses were collected as physical copies coded and data entered in Microsoft Excel. A signed consent form was obtained from all respondents in the study. Completed questionnaires that were received were coded and data entered into the Excel sheet by the researcher. A double entering technique ensured correctness of data entered. Data access was available only to the researcher.

\section{Results}

Of the 650 questionnaires sent out, 425 responses were received whilst 25 questionnaires were incomplete and could

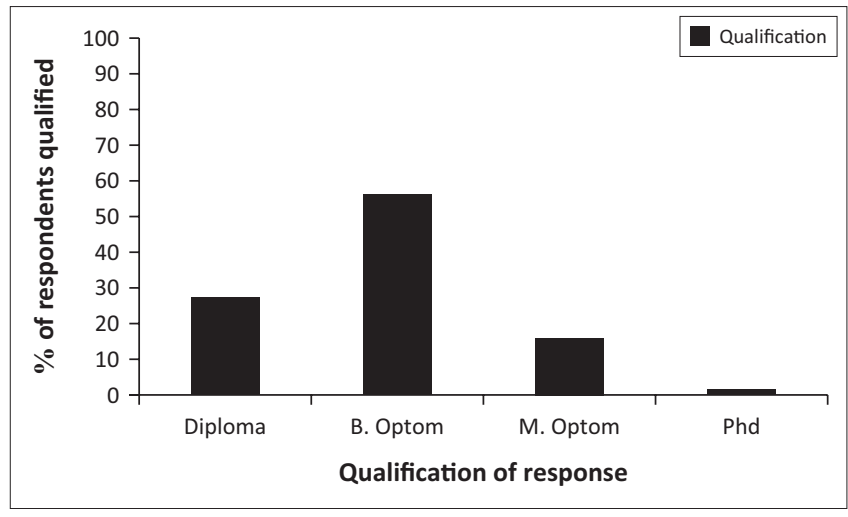

B. Optom, Bachelor of Optometry; M. Optom, Master of Optometry; Phd, Doctor of Philosophy.

FIGURE 1: Qualification of respondents in the study.

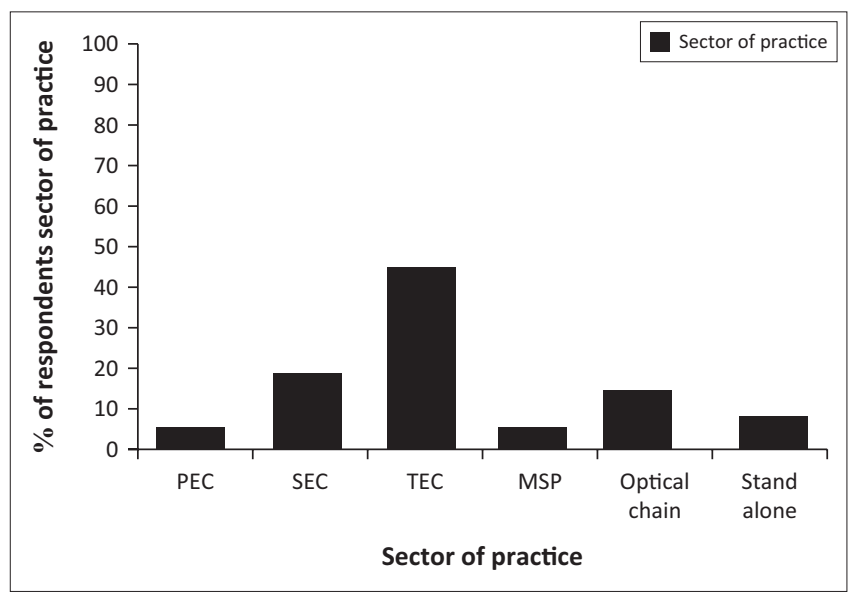

PEC, primary eye centre; SEC, secondary eye care centre; TEC, tertiary eye care centre; MSP, multi-speciality hospital.

FIGURE 2: Sector of practice of respondents in the study.

notbe used for analysis. From the 400 completed questionnaires (response rate, 62\%), 52\% $(n=207)$ were males and $48 \%(n=$ 193) were females with ages between 19 years and 58 years (median: 26 years and mean age and standard deviation [s.d.] of $29 \pm 8$ years). The qualification of the respondents ranged 
from a diploma to a $\mathrm{PhD}$ in optometry, although the majority $(57 \%)$ of the respondents were bachelor's degree graduates in optometry (Figure 1). The respondents were geographically distributed across the country; however slightly less than half $(41 \%)$ of the respondents were from the south zone (southern part of India).

Most respondents (86\%) rendered optometry eye care services in the private sector whilst only $14 \%$ were in the public sector. Amongst the public sector optometrists, 50\% were diploma holders. The study respondents were practising in hospitals, optical outlets and stand-alone practices as shown in Figure 2.

The responses by the 400 optometrists to the 14 skill sets listed in the questionnaire were statistically analysed using the chi-square test. The mean knowledge, skill level and frequency of skill utilisation amongst public and private sector optometrists along with their $p$-values are given in Table 1. The mean knowledge, skill level and frequency of skill utilisation between public and private sector optometrists in the study highlighted in orange indicate values less than $60 \%$ whilst significant $p$-values are highlighted in mauve (Table 2). The overall results for each of the 14 skills sets in the questionnaire are presented in Table 2 . The overall percentage score of respondents were taken, taking the median score of three and above on Likert scale representing responses good, very good and excellent for knowledge and skill level. For frequency of skill utilisation, the median score of three above on Likert scale was taken indicating responses sometimes, often and always.

A statistically significant difference (Table 2) in knowledge level between public and private sector optometrists was noted in all skill sets except history taking, subjective evaluation, contact lens, optical dispensing, indirect ophthalmoscopy, community/public health activities and referrals. The knowledge level in ancillary and diagnostic tests $(69 \%)$ was the least amongst public sector optometrists whilst it was the least in indirect ophthalmoscopy $(66 \%)$ for private sector optometrists (Table 2). Significant differences in skill level were noted between public and private sector optometrists in most skill sets except history taking, subjective evaluation, optical dispensing, community/public health activities and referrals. The public sector optometrists showed least skill levels in indirect ophthalmoscopy (56\%) and ancillary and diagnostic tests $(62 \%)$ whilst the private sector optometrists showed least skill levels in indirect ophthalmoscopy (44\%) and direct ophthalmoscopy (DO) (52\%) (Table 2).

Indirect ophthalmoscopy (13\%) and ancillary and diagnostic tests $(37 \%)$ showed the least frequency of skill utilisation amongst public sector optometrists whilst it was indirect ophthalmoscopy (34\%) and DO (43\%) for private sector optometrists. Statistically significant difference in frequency of skill utilisation was noticed in all skill sets between public and private sector optometrists except history taking and DO (Table 1). The overall analyses indicate that there is statistically significant difference in knowledge level $(p=0.034)$ and frequency of skill utilisation $(p=0.006)$ between public and private sector optometrists as seen in Table 2.

In the study, $50 \%$ of the respondents working in the public sector were diploma holders and $14 \%$ of the optometrists in the study were rendering services in the public sector. An overall analysis of the knowledge, skill level and frequency of optometry skill utilisation between diploma and degree holders was carried out. Knowledge level amongst diploma holders was the least in indirect ophthalmoscopy (50\%), followed by DO (59\%) and low vision evaluation (63\%) whilst in degree holders, it was least in indirect ophthalmoscopy (76\%), followed by ancillary and diagnostic tests $(84 \%)$, DO $(87 \%)$ and contact lens (87\%) (Table 2). The skill level amongst diploma holders was the least in indirect ophthalmoscopy (33\%), DO (49\%) and low vision evaluation (54\%) whilst in degree holders it was the least in indirect ophthalmoscopy (42\%), DO (69\%) and ancillary and diagnostic tests (76\%). A statistically significant difference (Table 3) in knowledge level between diploma and degree holders was noted in majority of the skill sets except history taking, optical dispensing, community/public health activities, referrals and record keeping. Amongst skill levels a statistically significant difference (Table 3) has been noted in all skill sets except history taking, optical dispensing, ancillary and diagnostic tests, indirect ophthalmoscopy, community/public health activities, referrals and record keeping.

The frequency of skill utilisation amongst diploma holders was the least in indirect ophthalmoscopy (14\%), DO (26\%) and low vision evaluation (37\%) whilst amongst degree holders it was the least in indirect ophthalmoscopy (28\%), DO $(48 \%)$ and ancillary and diagnostic tests (54\%). A statistically significant difference (Table 3) in frequency of skill utilisation between diploma and degree holders was noted in majority of the skill sets except optical dispensing, ancillary and diagnostic tests, DO, indirect ophthalmoscopy, community/ public health activities, referrals and record keeping.

The overall analysis of the knowledge, skill and frequency of skill utilisation was carried out based on education level between diploma and degree holders in optometry, and it revealed that there is statistically significant difference in overall knowledge $(p=0.002)$, skill level $(p=0.024)$ and frequency of skill utilisation $(p=0.042)$ between diploma and degree holders in the study as seen in Table 2.

\section{Discussion Knowledge level}

The study revealed that the knowledge levels of optometrists was high in almost all the skills listed in the questionnaire, with the least being in indirect ophthalmoscopy, ancillary and diagnostic tests, and DO. Knowledge influences the skill level or competence and gives the optometrist the confidence to perform a skill. A previous study conducted in India in 2015 reported that optometrists with post- 
TABLE 2: Overall analysis of knowledge, skill level and frequency of optometry skill utilisation between diploma and degree sector holders of optometry in the study.

\begin{tabular}{|c|c|c|c|c|c|c|c|c|c|c|}
\hline \multirow[t]{2}{*}{$\begin{array}{l}\text { Item } \\
\text { number }\end{array}$} & \multirow[t]{2}{*}{ List of skills } & \multicolumn{2}{|c|}{ Knowledge level (\%) } & \multirow[t]{2}{*}{$p$} & \multicolumn{2}{|c|}{ Skill level (\%) } & \multirow[t]{2}{*}{$p$} & \multicolumn{2}{|c|}{$\begin{array}{l}\text { Frequency of skill } \\
\text { utilisation }(\%)\end{array}$} & \multirow[t]{2}{*}{$p$} \\
\hline & & Diploma & Degree & & Diploma & Degree & & Diploma & Degree & \\
\hline 1 & History taking & 99.1 & 99.3 & 0.796 & 98.1 & 99.3 & 0.291 & 95.3 & 99.3 & $0.007 * *$ \\
\hline \multirow{5}{*}{2} & Retinoscopy & 97.2 & 99.3 & 0.091 & 93.5 & 95.9 & 0.309 & 92.5 & 98.0 & $0.009 * *$ \\
\hline & $A R$ & 98.1 & 99.0 & 0.501 & 98.1 & 98.0 & 0.91 & 88.8 & 86.3 & 0.521 \\
\hline & NOT & 84.1 & 97.3 & $<0.001 * * *$ & 81.3 & 94.5 & $<0.001 * * *$ & 62.6 & 75.1 & $0.014 *$ \\
\hline & Pupil evaluation & 93.5 & 98.0 & $0.025 *$ & 91.6 & 97.6 & $0.007 * *$ & 82.2 & 92.2 & $0.004 * *$ \\
\hline & Overall analysis & 93.0 & 98.0 & $0.019 *$ & 91.6 & 97.4 & $0.002 * *$ & 80.2 & 88.0 & $0.005^{* *}$ \\
\hline \multirow[t]{8}{*}{3} & Subjective evaluation & & & & & & & & & \\
\hline & Visual Acuity & 100.0 & 99.7 & 0.545 & 98.1 & 99.3 & 0.291 & 98.1 & 99.0 & 0.501 \\
\hline & Subjective refraction & 98.1 & 98.3 & 0.913 & 96.3 & 98.3 & 0.225 & 93.5 & 96.9 & 0.117 \\
\hline & $\mathrm{JCC}$ & 74.8 & 94.9 & $<0.001 * * *$ & 71.0 & 89.4 & $<0.001 * * *$ & 53.3 & 74.1 & $<0.001 * * *$ \\
\hline & Duochrome & 79.4 & 95.6 & $<0.001 * * *$ & 76.6 & 90.4 & $<0.001 * * *$ & 70.1 & 91.5 & $<0.001^{* * *}$ \\
\hline & Fogging & 87.9 & 96.6 & $<0.001 * * *$ & 86.0 & 95.2 & 0.002 & 81.3 & 92.2 & $0.002 * *$ \\
\hline & Prescription writing & 99.1 & 98.3 & 0.574 & 99.1 & 97.6 & 0.358 & 96.3 & 96.6 & 0.875 \\
\hline & Overall analysis & 87.0 & 97.0 & $<0.001 * * *$ & 86.0 & 95.0 & $<0.001 * * *$ & 80.0 & 91.0 & $0.002 * *$ \\
\hline \multirow[t]{8}{*}{4} & Slit lamp evaluation & & & & & & & & & \\
\hline & Anterior segment & 81.3 & 93.9 & $<0.001 * * *$ & 78.5 & 92.5 & $<0.001 * * *$ & 68.2 & 81.2 & 0.006 \\
\hline & Anterior chamber & 81.3 & 92.2 & $0.002 * *$ & 78.5 & 86.7 & 0.045 & 62.6 & 78.2 & $0.002 * *$ \\
\hline & Crystalline lens & 79.4 & 94.5 & $<0.001 * * *$ & 72.0 & 90.1 & $<0.001 * * *$ & 57.9 & 78.5 & $<0.001 * * *$ \\
\hline & Gonioscopy & 39.3 & 71.7 & $<0.001 * * *$ & 22.4 & 52.9 & $<0.001 * * *$ & 8.4 & 31.4 & $<0.001 * * *$ \\
\hline & Applanation Tonometry & 72.0 & 90.1 & $<0.001 * * *$ & 66.4 & 86.0 & $<0.001 * * *$ & 47.7 & 61.1 & 0.016 \\
\hline & TBUT & 77.6 & 94.2 & $<0.001 * * *$ & 70.1 & 91.5 & $<0.001 * * *$ & 52.3 & 71.3 & $<0.001 * * *$ \\
\hline & Overall analysis & 72.0 & 90.1 & $<0.001 * * *$ & 65.3 & 84.0 & $<0.001 * * *$ & 50.4 & 67.0 & $<0.001 * * *$ \\
\hline \multirow[t]{4}{*}{5} & Binocular vision evaluation & & & & & & & & & \\
\hline & Diagnostic parameters & 69.2 & 93.2 & $<0.001 * * *$ & 62.6 & 87.7 & $<0.001 * * *$ & 48.6 & 73.0 & $<0.001 * * *$ \\
\hline & Sensory status & 61.7 & 90.4 & $<0.001 * * *$ & 55.1 & 85.7 & $<0.001 * * *$ & 44.9 & 70.0 & $<0.001 * * *$ \\
\hline & Overall analysis & 66.0 & 92.0 & $<0.001 * * *$ & 61.3 & 87.7 & $<0.001 * * *$ & 47.4 & 72.0 & $<0.001 * * *$ \\
\hline \multirow[t]{10}{*}{6} & Contact lens & & & & & & & & & \\
\hline & $\mathrm{SCL}$ & 84.1 & 93.2 & 0.006 & 79.4 & 86.3 & 0.091 & 61.7 & 71.3 & 0.065 \\
\hline & Patient instruction & 83.2 & 93.5 & $0.002 * *$ & 79.4 & 91.8 & $<0.001 * * *$ & 66.4 & 77.1 & $0.029 *$ \\
\hline & RGP & 54.2 & 84.3 & $<0.001 * * *$ & 46.7 & 79.5 & $<0.001 * * *$ & 30.8 & 56.7 & $<0.001 * * *$ \\
\hline & Patient Instruction & 54.2 & 86.7 & $<0.001 * * *$ & 49.5 & 83.3 & $<0.001 * * *$ & 33.6 & 62.5 & $<0.001 * * *$ \\
\hline & Tonic fens & 62.6 & 86.7 & $<0.001 * * *$ & 54.2 & 82.9 & $<0.001 * * *$ & 41.1 & 63.8 & $<0.001 * * *$ \\
\hline & Cosmetic lens & 67.3 & 89.4 & $<0.001 * * *$ & 61.7 & 82.9 & $<0.001 * * *$ & 50.5 & 58.4 & 0.159 \\
\hline & CL complications & 64.5 & 87.7 & $<0.001 * * *$ & 55.1 & 77.8 & $<0.001 * * *$ & 50.5 & 56.0 & 0.328 \\
\hline & Specialty $\mathrm{CL}$ & 51.4 & 72.0 & $<0.001 * * *$ & 43.0 & 59.4 & 0.004 & 27.1 & 34.8 & 0.146 \\
\hline & Overall analysis & 65.7 & 87.2 & $<0.001 * * *$ & 59.2 & 81.0 & $<0.001 * * *$ & 44.7 & 60.0 & $<0.001 * * *$ \\
\hline \multirow[t]{7}{*}{7} & Low vision evaluation & & & & & & & & & \\
\hline & Low vision patient identifid & 70.1 & 94.2 & $<0.001 * * *$ & 59.8 & 92.8 & $<0.001 * * *$ & 37.4 & 62.8 & $<0.001 * * *$ \\
\hline & $\begin{array}{l}\text { Ability to prescribe low vision devices as per } \\
\text { patient needs }\end{array}$ & 58.9 & 92.2 & $<0.001 * * *$ & 52.3 & 87.7 & $<0.001 * * *$ & 32.7 & 60.4 & $<0.001 * * *$ \\
\hline & Patient instruction & 67.3 & 91.8 & $<0.001 * * *$ & 59.8 & 88.7 & $<0.001 * * *$ & 43.0 & 64.2 & $<0.001 * * *$ \\
\hline & Monitoring and evaluation & 58.9 & 88.7 & $<0.001 * * *$ & 49.5 & 85.3 & $<0.001 * * *$ & 37.4 & 55.3 & $0.002 * *$ \\
\hline & Rehabilitation and further referrals & 61.7 & 83.3 & $<0.001 * * *$ & 50.5 & 78.5 & $<0.001 * * *$ & 37.4 & 49.1 & $0.037 *$ \\
\hline & Overall analysis & 62.7 & 90.1 & $<0.001 * * *$ & 53.7 & 86.7 & $<0.001 * * *$ & 37.4 & 58.7 & $0.002 * *$ \\
\hline 8 & Optical dispensing & & & & & & & & & \\
\hline & Ability to interpret prescription & 94.4 & 97.3 & 0.166 & 94.4 & 96.9 & 0.237 & 91.6 & 94.2 & 0.349 \\
\hline & Previous spectacle prescripts & 94.4 & 97.6 & 0.108 & 94.4 & 98.6 & $0.016^{*}$ & 89.7 & 93.2 & 0.253 \\
\hline & Frame selection and ophthalmic lens selection & 91.6 & 98.0 & $0.003 * *$ & 91.6 & 88.4 & 0.361 & 77.6 & 75.8 & 0.708 \\
\hline & $\begin{array}{l}\text { Ability to perform face and frame measurements } \\
\text { and markings }\end{array}$ & 86.0 & 90.4 & 0.202 & 84.1 & 87.0 & 0.453 & 70.1 & 73.4 & 0.515 \\
\hline & $\begin{array}{l}\text { Ability to order and verify the ordered lenses } \\
\text { against the prescription prior to delivery }\end{array}$ & 86.9 & 93.2 & $0.047^{*}$ & 86.0 & 86.7 & 0.854 & 72.9 & 74.4 & 0.761 \\
\hline & $\begin{array}{l}\text { Patient instruction on spectacle use, care and } \\
\text { maintenance }\end{array}$ & 93.5 & 99.7 & $<0.001 * * *$ & 91.6 & 82.5 & 0.765 & 83.2 & 86.0 & 0.48 \\
\hline & $\begin{array}{l}\text { Ability to manage patients with complaints } \\
\text {-troubleshooting }\end{array}$ & 91.6 & 96.6 & $0.037 *$ & 91.6 & 87.7 & 0.278 & 79.4 & 81.9 & 0.575 \\
\hline
\end{tabular}


TABLE 2 (Continues...): Overall analysis of knowledge, skill level and frequency of optometry skill utilisation between diploma and degree sector holders of optometry in the study.

\begin{tabular}{|c|c|c|c|c|c|c|c|c|c|c|}
\hline \multirow[t]{2}{*}{$\begin{array}{l}\text { Item } \\
\text { number }\end{array}$} & \multirow[t]{2}{*}{ List of skills } & \multicolumn{2}{|c|}{ Knowledge level \% } & \multirow[t]{2}{*}{$p$} & \multicolumn{2}{|c|}{ Skill level \% } & \multirow[t]{2}{*}{$p$} & \multicolumn{2}{|c|}{$\begin{array}{l}\text { Frequency of skill } \\
\text { utilisation } \%\end{array}$} & \multirow[t]{2}{*}{$p$} \\
\hline & & Diploma & Degree & & Diploma & Degree & & Diploma & Degree & \\
\hline \multirow[t]{13}{*}{9} & Ancillary and diagnostic tests & & & & & & & & & \\
\hline & Amsler test & 73.5 & 96.2 & $<0.001 * * *$ & 47.7 & 92.8 & $<0.001 * * *$ & 47.7 & 75.6 & $<0.001 * * *$ \\
\hline & Colour vision test & 90.7 & 98.3 & $<0.001 * * *$ & 91.6 & 97.6 & $0.007 * *$ & 83.2 & 90.1 & 0.057 \\
\hline & Confrontation test & 73.8 & 94.2 & $<0.001 * * *$ & 69.2 & 91.1 & $<0.001 * * *$ & 48.6 & 66.9 & $<0.001 * * *$ \\
\hline & Diplopia charting & 67.3 & 90.1 & $<0.001 * * *$ & 60.0 & 84.6 & $<0.001 * * *$ & 37.46 & 60.8 & $<0.001 * * *$ \\
\hline & Topography & 60.7 & 88.4 & $<0.001 * * *$ & 47.7 & 76.8 & $<0.001 * * *$ & 29.9 & 54.6 & $<0.001 * * *$ \\
\hline & FFA & 54.2 & 73.0 & $<0.001 * * *$ & 43.9 & 61.8 & $0.002 * *$ & 23.4 & 28.0 & 0.355 \\
\hline & OCT & 57.9 & 81.2 & $<0.001 * * *$ & 43.9 & 65.5 & $<0.001 * * *$ & 29.0 & 49.1 & $<0.001 * * *$ \\
\hline & HRT & 32.7 & 54.9 & $<0.001 * * *$ & 23.4 & 36.5 & $0.013^{*}$ & 13.1 & 15.0 & 0.627 \\
\hline & UFA & 68.2 & 90.8 & $<0.001^{* * *}$ & 60.7 & 84.3 & $<0.001 * * *$ & 42.1 & 62.8 & $<0.001 * * *$ \\
\hline & A-scan & 76.6 & 88.1 & $0.005^{* *}$ & 70.1 & 76.8 & 0.171 & 54.2 & 55.6 & 0.800 \\
\hline & B-Scan & 57.9 & 78.5 & $<0.001 * * *$ & 43.9 & 67.6 & $<0.001 * * *$ & 23.4 & 34.1 & $0.0400 *$ \\
\hline & Overall analysis & 65.4 & 84.2 & $<0.001 * * *$ & 56.8 & 76.4 & $<0.001 * * *$ & 38.7 & 53.6 & $<0.001 * * *$ \\
\hline 10 & Direct ophthalmoscopy & 58.7 & 86.7 & $<0.001 * * *$ & 49.2 & 68.3 & $0.002 * *$ & 26.2 & 47.6 & 0.260 \\
\hline 11 & Indirect ophthalmoscopy & 49.7 & 76.0 & $0.006 * *$ & 33.0 & 42.0 & 0.246 & 14.4 & 28.2 & 0.214 \\
\hline \multirow[t]{4}{*}{12} & Community/public health activities & & & & & & & & & \\
\hline & Screening camps & 95.4 & 97.8 & 0.112 & 93.7 & 97.0 & 0.145 & 86.0 & 86.0 & 1.000 \\
\hline & Awareness camps & 94.2 & 96.7 & 0.345 & 92.0 & 95.7 & 0.148 & 76.0 & 76.0 & 1.000 \\
\hline & Overall analysis & 95.4 & 97.8 & 0.112 & 93.0 & 97.0 & 0.139 & 81.0 & 81.0 & 1.000 \\
\hline 13 & Referrals & 90.8 & 97.0 & 0.098 & 89.2 & 95.0 & 0.082 & 83.0 & 83.0 & 1.000 \\
\hline 14 & Recordkeeping & 93.0 & 95.0 & 0.437 & 90.0 & 92.0 & 0.386 & 79.0 & 85.0 & 0.425 \\
\hline 15 & Overall analysis & 78.0 & 92.0 & $0.002 * *$ & 72.0 & 85.0 & $0.024 *$ & 60.0 & 71.0 & $0.042 *$ \\
\hline
\end{tabular}

AR, autorefraction; NCT, non contact tonometry; JCC, Jackson's cross cylinder; TBUT, tear break up time; SCL, soft contact lens; RGP, rigid gas permeable; CL, contact lens; FFA, fundus flourescein angiopgraphy; OCT, optical coherence tomography; HRT, Heidelberg retina tomograph; HFA, Humphrey field analyser.

*, Significant; ${ }^{* *}$, highly significant; ${ }^{* *}$, very high significant.

graduate qualifications in optometry understood the importance of investigations and comprehensive clinical examination and were more confident in performing them. This indicated that optometrists with undergraduate qualification in optometry are not sufficiently prepared in terms of knowledge and training, denying them the confidence to offer comprehensive eye care services. ${ }^{4}$ Primary eye care forms an integral part of comprehensive eye care and should target not only blindness and visual impairment but should also address ocular morbidity. ${ }^{14}$ The components that constitute primary eye care such as eye health education, symptom identification, visual measurement, basic eye examination, diagnosis and timely referral should be part of the training for optometrists. ${ }^{14}$

Fundus examination completes the eye examination and forms an integral aspect of any primary eye examination. The study reported of $79 \%$ and $69 \%$ of knowledge of direct and indirect ophthalmoscopy, respectively. Poor knowledge of ophthalmoscopy, direct or indirect, negatively impacts on the usage of the skill as shown in the present study which showed that fundus examination was the least performed skill which correlates with their poor skill utilisation. Ophthalmoscopy forms a critical and most important part of an eye exam as it can provide valuable information about eye and general health and decide upon treatment options. Ancillary and diagnostic tests help confirm diagnosis and rule out differential diagnosis. The study also revealed that the knowledge level of diploma holders was significantly less than that of the degree holders in all the skill sets under consideration except for history taking. The absence of a competency-based framework for different cadres of optometry in India leads to confusion in the scope of practice, hence the discrepancies in knowledge in the study findings.

\section{Skill level}

This study found that except for history taking, all the other skills listed in the questionnaire showed low skill levels compared to knowledge level. Furthermore, the study established that the skill level for diploma holders was significantly less than that of degree holders. It should be noted, however, that the skill level was self-reported and indicated their perceived level of competence. The overall reported low level of skill compared to knowledge level could be attributed to less exposure to the practical aspect of the skill; hence, the theoretical knowledge could be sound but the work-based limitation in the practical aspect compromises the optometrist's ability to confidently perform a particular skill. The low skill level could also be attributed to the absence of clinical training, which is the most essential element of any optometry programme. The reasons for this could be lack of equipment for clinical training, lack of teaching faculties for training as well as lack of clinical training knowledge and assessment in teaching faculties in schools and colleges across the country. The absence of accredited standards or curricula for allied ophthalmic personnel has been cited by Arora et al which stressed the need for competency-based assessment using clinical-rubrics to assess the knowledge and skill levels. ${ }^{15}$ Innovative approaches in teaching and assessment could potentially help determine the gaps in knowledge and skills, making learning a great and holistic experience. ${ }^{16}$ 


\section{Frequency of utilisation of skills}

The results indicate that the respondents in the study routinely performed history taking as well as objective and subjective evaluation. The results correlate with a previous study conducted in India by Thite et al. ${ }^{4}$ The results for frequency of utilisation of slit lamp reveal that gonioscopy and applanation tonometry were the least performed skills, which also correlate with their knowledge and skill level.

A study conducted on urban and rural school children in Tamil Nadu, India reported a high prevalence of nonstrabismic binocular vision anomalies which increased with increasing age and recommended routine screening for binocular vision anomalies. ${ }^{17}$ The results of this study indicate that binocular vision evaluation is not a routinely performed skill in practice and this finding correlates with the previous study by Thite et $\mathrm{al}^{4}{ }^{4}$ which reported that only $45 \%$ of the respondents in the study routinely performed binocular vision evaluation. The present study revealed that knowledge and skill levels in binocular vision evaluation were $85 \%$ and $80 \%$, respectively, whilst skill utilisation in binocular vision evaluation was only $65 \%$ indicating that binocular vision evaluation was not a routinely performed skill although it was higher compared to the findings in the previous study conducted by Thite et al. ${ }^{4}$ The results suggest that binocular vision evaluation is not a routinely performed skill. Both public and private sector optometrists did not routinely perform these tests even though a high prevalence of nonstrabismic binocular vision anomalies has been reported and constitutes part of the comprehensive optometric examination based on the WCO guidelines.

The study found that the frequency of utilisation of skills under contact lenses and low vision evaluation is significantly low as compared to knowledge and skill level, which is comparable to a previous study by Thite et al. ${ }^{4}$ These results indicate either poor sources of low vision aids and contact lenses or insufficient training in these skills. A survey seeking to profile optometrists and optometric practices in Ghana revealed that history taking, DO, visual acuity, slit lamp biomicroscopy and retinoscopy were the most frequently performed procedures whilst the least performed procedures were contact lens and low vision assessments. ${ }^{18}$ Another study conducted in South Africa revealed that case history, visual acuity and ophthalmoscopy were routinely performed skills whilst slit lamp examination and non-contact tonometry were the least performed skills. ${ }^{19}$ This is consistent with the low uptake of contact lenses in the developing world.

Ancillary and diagnostic tests such as colour vision tests, confrontation tests, perimetry, Optical Coherence Tomography (OCT), Fundus Fluorescein Angiography (FFA) and A-scan Ultrasound were the least performed after ophthalmoscopy, indicating that optometrists in India are not utilised for such diagnostic services. The ancillary and diagnostic tests help confirm or rule out differential diagnosis; they enable in-depth assessment and identification of ocular and possible effects of systemic diseases. Optometrists play a vital role in diagnosing ocular disease and complementing the services of ophthalmologists to reduce the burden of preventable blindness ${ }^{18,19,20,21}$ Diagnostic skills should be integral in optometry training and service delivery. The results of this study concurred with the study by Thite et al confirming that diagnostic skills as well as the frequency of performing these skills are low in both public and private sectors optometrists. ${ }^{4}$

The fundus examination is an essential and routinely performed component of comprehensive eye examination that detects diabetic retinopathy and other highly prevalent conditions such as hypertensive retinopathy, vasculitis, Central Retinal Artery Occlusion (CRAO) and Central Retinal Vein Occlusion (CRVO). ${ }^{22}$ This study revealed that only $42 \%$ of the respondents in the study performed DO as against $100 \%$ in a study conducted in Ghana on optometrists, indicating that this skill was performed routinely in every practice. ${ }^{18}$ Another study conducted in Ireland indicated that DO was their first technique of choice for the fundus examination. ${ }^{23}$ A previous study conducted in India on practice patterns also revealed that only $21 \%$ of optometrists routinely performed DO whilst 50\% performed only when indicated, thus indicating that the fundus examination is not part of routine optometry eye care examination in India. ${ }^{4}$ The increasing prevalence of systemic conditions like diabetes and hypertension necessitates a fundus examination and ancillary tests to detect ocular manifestations of these systemic conditions. The role of an optometrist in primary eye care is incomplete without the fundus examination, which should be routinely carried out, and be an integral component of all eye care practices. Comprehensive eye examinations help in screening and early detection of common eye diseases, thus reducing morbidity and the burden of avoidable blindness. ${ }^{22}$ The overall analysis shows that optometrists' knowledge and skill levels are underutilised owing to a lack of confidence from poor training and/or lack of equipment needed in performing certain clinical skills in a given setup as well as an ill-defined scope of practice.

\section{Comparison of knowledge, skill level and utilisation of skills between diploma and degree holders in the study}

A comparison of the levels of knowledge and skills and frequency of utilisation of skills between diploma and degree holders involved in the study revealed a significant difference in knowledge level in all the skills between diploma and degree holders except in auto-refraction (AR). Under skill level and frequency of utilisation of skills, there were significant differences between degree and diploma holders, except for AR, ability to order and verify the ordered lenses against prescription prior to delivery, patient instruction on spectacle use, care and maintenance, ability to manage patients with complaints, indirect ophthalmoscopy, screening camps, awareness programmes and record keeping. This was expected considering the limited role played by the cadres and their involvement in screening programmes and optical dispensing. 
In this study, $24 \%$ of the respondents worked either in optical chains or stand-alone practices, hence the overlap in work for both diploma and degree holders, a finding highlighted under optical dispensing, wherein no significant difference is noticeable in skill level and frequency of skill utilisation. The study revealed that the frequency of skill utilisation is not significantly different, meaning that diploma and degree holders end up delivering the same services and functions despite the differences in their knowledge and skills. The importance of this aspect, that is the differences in knowledge and skills is discussed by Murthy and Raman in the 2009 study who posited that primary eye care is an integral part of comprehensive eye care and further highlighted the importance of defining the knowledge and skill requirements of primary eye care workers in the eye health delivery system. ${ }^{14}$ Studies reveal that inadequate training and support impede the implementation of training programmes, resulting in poor knowledge and skills amongst eye care professionals and the resultant substandard service delivery. ${ }^{24,25}$

\section{Limitations of the study}

The knowledge, skills and utilisation of optometry skills were self-reported (questionnaire-based study) and may not have been truly reflective of the service delivery although the questionnaire was constructed in such a way that it established the capabilities of optometrists against what they are currently practising. The absence of a central registry for optometrists in the country has led to unequal representation of public and private sector optometrists in this study as well as the number of respondents given the size of the country, which could be a limitation of the study.

\section{Conclusion}

There is a significant underutilisation of skills amongst public and private sector optometrists with significant disparities in knowledge and skills between diploma and degree holders in optometry in India. Despite these differences, both end up providing eye care services. Optometrists are mostly involved in refraction and optical dispensing services whilst important ancillary and diagnostic tests were the skills least performed by practising optometrists after ophthalmoscopy. Systemic health conditions such as diabetes, hypertension and obesity are reaching epidemic levels and optometrists can play an important role in the early detection of sight-threatening complications caused by these systemic diseases. This study suggests that optometrists are better suited for diagnostic and management roles in terms of dealing with ocular and systemic conditions through appropriate education and training; therefore, they can contribute effectively towards averting preventable blindness. Optometrists can thus be better utilised in both the public and private sectors to offer comprehensive eye care services to the benefit of the patient. It can be concluded that failure to mandate the best practice standards, coupled with an ill-defined scope of practice, results in the underutilisation of optometry services in public and private sectors. A well-defined scope of practice for degree and diploma optometrists in the public and private sectors could enhance their roles and improve vision and eye health across the country.

\section{Acknowledgements Competing interests}

The authors declare that they have no financial or personal relationships that may have inappropriately influenced them in writing this article.

\section{Authors' contributions}

A.A., K.N. and P.C.F. were involved in concept, design, data analysis, manuscript writing and editing. A.A. was involved in data collection and statistical analysis. K.N. and P.C.F. were involved in manuscript review.

\section{Funding information}

This research received no specific grant from any funding agency in the public, commercial or not-for-profit sectors.

\section{Data availability}

The data in addition to the ones provided in this article that support the findings of the study are available from the corresponding author, $\mathrm{AA}$, upon reasonable request.

\section{Disclaimer}

The views and opinions expressed in this article are those of the authors and do not necessarily reflect the official policy or position of any affiliated agency of the authors.

\section{References}

1. Leasher J, Pike S. Optometry in the Americas [homepage on the Internet]. New York, NY: Old Post Publishing; 2009 [cited 2019 Dec 1]; p. 1-38. Available from: http://www.paho.org

2. Padilla MA, Di Stefano AF. A snapshot of optometry around the world [homepage on the Internet]. Review Optom, 2009 [cited 2019 Dec 1]; p. 146. Available from: the Internet]. Review Optom, 2009 [cited $2019 \mathrm{Dec} 1]$; p. 146. Available from: https://ww
the-world.

3. Kambli R. The need for eyecare is not only a massive challenge but an immense opportunity. Noida, India: The Indian Express; 2011.

4. Thite N, Jaggernath J, Chinanayi F, Bharadwaj S, Kunjeer G. Pattern of optometry practice and range of services in India. Optom Vis Sci. 2015;92(5):615-622. https://doi.org/10.1097/OPX.0000000000000587

5. IOF. Delhi declaration on optometry and blindness prevention in India preamble [homepage on the Internet]. 2010 [cited 2016 Mar 14]. Available from: https:// docplayer.net/102590638-Delhi-declaration-on-optometry-and-blindnessprevention-in-india.html

6. De Souza N, Looi S, Shinde L, et al. The role of optometrists in India: An integral part of an eye health team. Indian J Ophthalmol. 2012;60(5):401. https://doi. org/10.4103/0301-4738.100534

7. Awan $\mathrm{H}$, Khan MD, Felch $\mathrm{W}$, et al. Status of ophthalmic education and the eye health workforce in South Asian Association for Regional Cooperation Countries. Asia-Pacific J Ophthalmol. 2014;3(2):74-82. https://doi.org/10.1097/APO.0000000000000037

8. Bogunjoko TJ, Hassan AO, Okonkwo O, et al. Impact of middle level eye care personnel on the delivery of eye care services in South-western Nigeria. Int Community Med Public Heal. 2018;5(3):871. https://doi.org/10.18203/2394-6040. ijcmph20180740

9. Prasad NM. Thoughts on establishing mid-level ophthalmic personnel for VISION 2020 in India. Community Eye Health J [serial online]. 2005 [cited 2019 Dec 15];18(55):112. Available from: https://www.cehjournal.org/article/thoughts-onestablishing-mid-level-ophthalmic-personnel-for-vision-2020-in-india/

10. Haryana Gazette. Service Rules of Para-Medical and Miscellaneous Posts (Group C) 1998. India: Health Department [document on the Internet]. 1998 [cited] Available from: http://haryanahealth.nic.in/DepartmentalServiceRules.html

11. Kerala Gazette. Paramedical bill 1-24 - PRS [statuet on the Internet]. Leg. Dated, No. 1084/Legn. 1/2007/Leg 2007 [cited]. Available from: https://www.yumpu. com/en/document/view/5553086/paramedical-bill-1-24-prs

12. MOHFW. The Gazette of India Extraordinary. New Delhi: Government of India, $2015 ;$ p. 32. 
13. Misra V, Vashist P, Malhotra S, Gupta SK. Models for primary eye care services in India. Indian J Community Med. 2015;40(2):79-84. https://doi.org/10.4103/09700218.153868

14. Murthy GVS, Raman U. Perspectives on primary eye care. Community eye Heal [serial online]. 2009 [cited 2019 Dec 15];22(69):10-11. Available from: http:// www.ncbi.nlm.nih.gov/pubmed/19506714

15. Arora S, Mathur U, Datta P. Competency-based assessment as a reliable skill building strategy for allied ophthalmic personnel. Community Eye Health J [serial online]. 2018 cited $2019 \mathrm{Dec} 20] ; 31(102): S 5-S 6$. Available from: https://www.
cehjournal.org/article/competency-based-assessment-as-a-reliable-skillbuilding-strategy-for-allied-ophthalmic-personnel/

16. Asokan R, Ramani K. Innovations in optometric education. Sci J Med Vis Res Found [serial online]. 2016 [cited 2019 Dec 20];XXXIV(1):11-14. Available from: https://www. researchgate.net/publication/311965523_Innovations_in_Optometric_Education

17. Hussaindeen JR, Shah P, Ramani KK, Ramanujan L. Efficacy of vision therapy in children with learning disability and associated binocular vision anomalies. Optom. 2018;11(1):40-48. https://doi.org/10.1016/j.optom.2017.02.002

18. Boadi-Kusi SB, Kyei S, Okyere VB, Abu SL. Factors influencing the decision of Med Educ. 2018;18(1):188. https://doi.org/10.1186/s12909-018-1302-3

19. Mashige KP, Naidoo KS. Optometric practices and practitioners in KwaZulu-Natal, South Africa*. Afr Vision Eye Health. 2010;69(2):77-85. https://doi.org/10.4102/ aveh.v69i2.128
20. Myint J, Edgar DF, Kotecha A, Murdoch IE, Lawrenson JG. A national survey of diagnostic tests reported by UK community optometrists for the detection of https://doi.org/10.1111/j.1475-1313.2011.00844.x

21. Oster J, Culham LE, Daniel R. An extended role for the hospital optometrist. Ophthalmic Physiol Opt. 1999;19(4):351-356. https://doi.org/10.1046/j.14751313.1999.00427.x

22. YadavS, Tandon R. Comprehensive eye examination: What does it mean? Community Eye Health J [serial online]. 2019 [cited 2019 Dec 26];32(107):1-2. Available from: http://www.cehjsouthasia.org/article/comprehensive-eye-examination-what-doesit-mean/

23. Barrett C, Loughman J. Expanding the traditional role of optometry: Current practice patterns and attitudes to enhanced glaucoma services in Ireland. $J$ Optom. 2018;11(4):252-261. https://doi.org/10.1016/j.optom.2018.02.004

24. Du Toit R, Palagyi A, Brian G. The development of competency-based education for mid-level eye care professionals: A process to foster an appropriate, widely accepted and socially accountable initiative. Educ Health [serial online]. 2010 Aug [cited 2019 Dec 15];23(2):368. Available from: http://www.ncbi.nlm.nih.gov/pubmed/20853239

25. Byamukama E, Courtright P. Knowledge, skills, and productivity in primary eye care among health workers in Tanzania: Need for reassessment of expectations? Int Health. 2010;2(4):247-252. https://doi.org/10.1016/j.inhe.2010.07.008 